\title{
Sodium channel blockers and uridine triphosphate: effects on nasal potential difference in cystic fibrosis mice
}

\author{
S. Ghosal*, C.J. Taylor*, W.H. Colledge ${ }^{\#}$, R. Ratcliff ${ }^{\#}$, M.J. Evans
}

\begin{abstract}
Sodium channel blockers and uridine triphosphate: effects on nasal potential difference in cystic fibrosis mice. S. Ghosal, C.J. Taylor, W.H. Colledge, R. Ratcliff, M.J. Evans. C)ERS Journals Ltd 2000.

ABSTRACT: Sodium channel inhibitors block the enhanced $\mathrm{Na}^{+}$reabsorption in cystic fibrosis (CF). Extracellular nucleotides facilitate $\mathrm{Cl}^{-}$secretion via $\mathrm{Ca}^{2+}$ gated $\mathrm{Cl}^{-}$ channels. A combination of these effects may produce less viscid secretions in $\mathbf{C F}$ which are easier to expectorate.

This study examined the effects of combining sodium channel blockers with uridine triphosphate (UTP) on nasal membrane potential difference (PD) in CF insertional null mutant mice (cftr $\left.{ }^{\text {tmIHGU }}\right), \Delta$ F508 homozygous mice $\left(\right.$ cftr $\left.^{\text {tm1 Cam }}\right)$ and matched control animals.

Median basal PD in the insertional CF mice and $\triangle F 508$ CF mice were -28 and $\mathbf{- 3 4}$ $\mathrm{mV}$ respectively. These values were significantly different to the control animals $(-20$ $\mathrm{mV})$. Amiloride and loperamide reduced the PD in $c f t{ }^{\mathrm{tmlHGU}} \mathrm{CF}$ mice $(\triangle \mathrm{PD} 13 \mathrm{mV} \&$ $15 \mathrm{mV}$ respectively) suggesting $\mathrm{Na}^{+}$blockade. The subsequent addition of UTP in a chloride-free vehicle increased the PD $(\Delta P D-8--12.5 \mathrm{mV}) . \Delta$ F508 mice showed significantly greater responses compared with $C F$ insertional null mutant mice $(\mathbf{p}<\mathbf{0 . 0 5})$. The action of UTP was brief and not prolonged by the addition $\alpha-\beta$ methylene-adenosine $5^{\prime}$ diphosphate. Suramin, a competitive antagonist of $P 2$ purinoceptors blocked the action of UTP.

In conclusion, this study demonstrated dose dependant nasal membrane potential changes in differences mice with uridine triphosphate in the presence of sodium channel blockers suggestive of chloride secretion. More stable analogues of uridine triphosphate in combination with long acting sodium channel blockers such as loperamide may have therapeutic potential in cystic fibrosis. Eur Respir J 2000; 15: 146-150.
\end{abstract}

*Division of Child Health, University of Sheffield, Sheffield, UK. "Dept of Physiology, Cambridge University, Cambridge, UK.

\author{
Correspondence: C.J. Taylor \\ Dept of Paediatrics \\ Sheffield Children's Hospital \\ Western Bank \\ Sheffield \\ S10 2TH \\ UK \\ Fax: 441142755364
}

Keywords: Cystic fibrosis mice nasal potential difference sodium channel blockers uridine triphosphate

Received: September 31998 Accepted after revision September 281999 S. Ghosal was funded by the Cystic Fibrosis Trust.

In cystic fibrosis $(\mathrm{CF})$ there is a profound change in epithelial fluid transport affecting various tissues, particularly the airway, where viscid respiratory secretions accumulate [1]. In the majority of patients with $\mathrm{CF}$, the cystic fibrosis transmembrane conductance regulator (CFTR), a chloride $\left(\mathrm{Cl}^{-}\right)$channel protein, is not expressed in the apical membrane [2]. This leads to defective cyclic adenosine monophosphate (cAMP) mediated chloride (and water) secretion. However, alternative calcium $\left(\mathrm{Ca}^{2+}\right)$ activated pathways of $\mathrm{Cl}^{-}$secretion are preserved [3]. CF airway epithelium also shows enhanced sodium $\left(\mathrm{Na}^{+}\right)$ absorption which also contributes to the dehydration of airway secretions [4]. Moreover, ineffective ciliary action prevents adequate clearance of mucus in the lumen of the airways [5], predisposing the patient to endobronchial infection and limiting the effect of host defence mechanisms and antibiotics.

Since the majority of CF subjects have no functional CFTR in the airway, the development of possible therapeutic agents has focused on sodium channel inhibitors and promoting non-CFTR $\mathrm{Cl}^{-}$channel function. Sodium channel inhibitors block the enhanced $\mathrm{Na}^{+}$reabsorption and thereby help to retain the hydration of secreted mucus [6]. Some investigators suggest that sodium channel blockers may have no effect on CF because of hypertonic $\mathrm{Cl}^{-}$concentration in the airway surface fluid [7]. Other investigators, however, have reported that the airway surface liquid is isotonic [8]. Extracellular nucleotides raise intracellular $\mathrm{Ca}^{2+}$ thus enhancing respiratory mucus hydration by facilitating $\mathrm{Cl}^{-}$secretion via $\mathrm{Ca}^{2+}$ gated $\mathrm{Cl}^{-}$ channels $[9,10]$. The authors would expect a combination of sodium blockers and $\mathrm{Ca}^{2+}$ activating nucleotide uridine triphosphate (UTP) acting via both pathways to produce less viscid secretions which are easier to expectorate [11].

Mouse models of CF are now available which share many electrophysiological properties with human airways $[12,13]$. Cultured cells from respiratory epithelia of CF mice show defective cAMP mediated $\mathrm{Cl}^{-}$conductance characteristic of the disease [14], and with increasing age, abnormalities in the lungs of these animals are being demonstrated [15]. The authors have examined the effect of inhaling two $\mathrm{Na}^{+}$channel inhibitors, amiloride or loperamide, combined with UTP on airway secretion by measuring changes in nasal epithelial potential difference (PD) of control (MF1) and CF mice.

Aims

To study the nasal PD changes using a combination of amiloride or loperamide and UTP in transgenic CF mice. 


\section{Methods}

\section{Experimental animals}

Twenty-four insertional null mutant $\mathrm{CF}$ mice $\left(c f t r^{\mathrm{tm} 1 \mathrm{HGU}}\right)[10]$ were studied in the experiments. Their breeding was subsidized by the Association Francaise de Lutte contre la Mucoviscidose, France and supplied by Charles River, Margate, Kent, UK. Twenty standard laboratory MF1 strain mice (Harlan, Bicester, Oxfordshire, UK) were used as controls. Both sexes were matched for age (range 3-14 months) and weighed 20-42 $\mathrm{g}$. The animals were allowed food and water ad libitum. A further group of seven $\mathrm{CF}$ mice homozygous for the $\Delta$ F508 mutation, $\left(c_{f t r}{ }^{\mathrm{tm} 1 \mathrm{Cam}}\right)[11]$ were also studied using the same protocols.

\section{Nasal potential difference measurements}

Mice were anaesthetized by intraperitoneal injection using a combination of ketamine $5 \mathrm{mg} \cdot 30 \mathrm{~g}^{\text {body weight }}{ }^{-1}$ and met-etomidate $0.05 \mathrm{mg} \cdot 30 \mathrm{~g}$ body weight ${ }^{-1}$. Nasal PD was measured as described previously [16] between a $24 \mathrm{G}$ exploring catheter filled with $0.1 \mathrm{M} \mathrm{KCl}$ and $2 \%$ agar and a teflon reference cannula inserted subcutaneously and perfused at $0.5 \mathrm{~mL} \cdot \mathrm{h}^{-1}$ with $0.9 \%$ saline through a syringe pump (Perfusor secura; B Braun). The two electrodes were connected to calomel half cells (Russell, Aucutermuchty, Fife, Scotland, UK) by salt-agar bridges containing $1 \mathrm{M} \mathrm{KCl}$ and $2 \%$ agar. Measurements were performed using a high impedance voltmeter (Model 602; Keithley Instruments, Reading, Berkshire, UK) and recorded with a Bio-Rad chart recorder (Bio-Rad, Hemel Hempstead, Hertfordshire, UK).

Nasal PD changes were measured in a stepwise manner as follows: 1) basal PD was measured and the maximum reading recorded; 2) the mice were then divided into two groups for administration of sodium blockers, group a) received nebulized amiloride (Sigma, Poole, Dorset, UK) 1 $\mathrm{mmol} \cdot \mathrm{L}^{-1}$ and group b) received nebulized loperamide (a gift from Janssen Pharmaceutica NV, Beerse, Belgium) 1 $\mathrm{mmol} \cdot \mathrm{L}^{-1}$, both for $2 \mathrm{~min}$. The nasal PD was measured after the completion of nebulization; 3 ) a subgroup of eight mice (four control animals and four insertional CF animals) were administered nebulized sodium gluconate $\left(\mathrm{Cl}^{-}\right.$free vehicle) $0.15 \mathrm{~mol} \cdot \mathrm{L}^{-1}$ after the sodium channel blocker; 4) finally nebulized UTP (Sigma, UK) 0.1-10 $\mathrm{mmol} \cdot \mathrm{L}^{-1}$ dissolved in $0.15 \mathrm{M}$ sodium gluconate was given to all mice in groups a) and b) and the PD was again measured. After each experiment the mice were given atipamezole $0.25 \mathrm{mg} \cdot 30 \mathrm{~g}$ body weight ${ }^{-1}$ as antidote for the met-etomidate to enable them to recover more quickly from the anaesthetic.

A Mann Whitney U-test was used to assess significance between groups and Wilcoxon signed rank test to assess significance within the groups. A project licence approval was obtained from the Home Office to carry out the procedures.

\section{Results}

Nasal membrane PD in mice were lumen negative. The resting nasal epithelial $P D$ in controls ranged $-12--27 \mathrm{mV}$
Table 1. - Potential difference (PD) changes in cystic fibrosis (CF) mice and control animals with the amiloride uridine triphosphate (UTP) combination

\begin{tabular}{lccc}
\hline Mouse type & $\begin{array}{c}\text { Basal PD } \\
\mathrm{mV}\end{array}$ & $\begin{array}{c}\Delta \mathrm{PD} \text { after } \\
\text { amiloride } 1.0 \\
\mathrm{mmol} \cdot \mathrm{L}^{-1} \\
\mathrm{mV}\end{array}$ & $\begin{array}{c}\Delta \mathrm{PD} \text { after } \\
\mathrm{UTP} 1.0 \\
\mathrm{mmol} \cdot \mathrm{L}^{-1} \\
\mathrm{mV}\end{array}$ \\
\hline $\begin{array}{l}\text { MF1 control } \\
\mathrm{n}=6\end{array}$ & $-20(-13--24)$ & 7 & -5 \\
$\begin{array}{l}\mathrm{CF} \text { insertional } \\
\mathrm{n}=10\end{array}$ & $-28(-20--36)^{*}$ & $13^{*}$ & $-8^{\#}$ \\
$\begin{array}{l}\text { CF } \Delta \mathrm{F} 508 \\
\mathrm{n}=7\end{array}$ & $-34(-25--39)^{* * * *}$ & $17^{* * * *}$ & $-15^{* * *}$ \\
\hline
\end{tabular}

Data are presented as the median with the range in parentheses. *: $\mathrm{p}<0.01 ;{ }^{\#}: \mathrm{p}<0.05$, comparison between control and CF groups. ${ }^{* *}: \mathrm{p}<0.05 ;: \mathrm{p}<0.01$, comparison between $\Delta \mathrm{F} 508$ and insertional $\mathrm{CF}$ groups.

(median $-20 \mathrm{mV}, \mathrm{n}=20$ ) and in cftr $^{\mathrm{tm} 1 \mathrm{HGU}}$ mice $-18--38$ $\mathrm{mV}$ (median $-28 \mathrm{mV}, \mathrm{n}=24)$. The $\Delta \mathrm{F} 508$ mice had a higher basal PD (range -25--39 mV, median $-34 \mathrm{mV}, \mathrm{n}=7$ ).

The changes in nasal PD after amiloride or loperamide administration were significant in both $\mathrm{CF}$ and control groups $(\mathrm{p}<0.01)$ compatible with sodium channel blockade. No significant PD changes were observed when sodium gluconate (low chloride vehicle) was administered after the sodium channel blockers. Subsequently UTP dissolved in $0.15 \mathrm{M}$ sodium gluconate increased PD in both groups, indicating that $\mathrm{Ca}^{2+}$ activated $\mathrm{Cl}^{-}$secretion was occurring. UTP given in $0.9 \%$ saline solution after sodium channel blockers were administered had no effect on PD. The PD changes after amiloride/loperamide and UTP administration were significant in the $c f t r^{\mathrm{tm} 1 \mathrm{HGU}}$ mice compared to controls ( $p<0.01$, tables 1 and 2$)$. Similar but larger PD responses were obtained in the $\Delta \mathrm{F} 508$ mice with sodium channel blocking agents and UTP (tables 1 and 2). An example of PD changes observed with the above combinations of drugs are shown in figures 1 and 2.

The duration of action of UTP (with the nasal mucosa in sodium blocked state after amiloride) is shown in figure 3. The PD changes after UTP were short lasting with PD reverting to the value of the post amiloride PD within 30-40 min following a single administration of 10.0

Table 2. - Potential difference (PD) changes in cystic fibrosis (CF) mice and control animals with the loperamide/ uridine triphosphate (UTP) combination

\begin{tabular}{lccc}
\hline Mouse type & $\begin{array}{c}\text { Basal PD } \\
\mathrm{mV}\end{array}$ & $\begin{array}{c}\Delta \text { PD after } \\
\text { loperamide } \\
1.0 \mathrm{mmol} \cdot \mathrm{L}^{-1} \\
\mathrm{mV}\end{array}$ & $\begin{array}{c}\Delta \mathrm{PD} \text { after } \\
\mathrm{UTP} 1.0 \\
\mathrm{mmol} \cdot \mathrm{L}^{-1} \\
\mathrm{mV}\end{array}$ \\
\hline $\begin{array}{c}\text { MF1 control } \\
\mathrm{n}=14\end{array}$ & $-22(-12--27)$ & 6 & -3 \\
$\begin{array}{c}\text { CF insertional } \\
\mathrm{n}=14\end{array}$ & $-28.5(-18--38)^{*}$ & $15^{*}$ & $-12.5^{*}$ \\
$\begin{array}{l}\mathrm{CF} \Delta \mathrm{F} 508 \\
\mathrm{n}=3\end{array}$ & $-34(-30--38)$ & 16 & -12 \\
\hline
\end{tabular}

Data are presented as the median with the range in parentheses. *: $\mathrm{p}<0.01$, comparison between control mice and insertional mutant mice. Statistical significance was not assessed in the $\Delta \mathrm{F} 508$ group due to small numbers. 


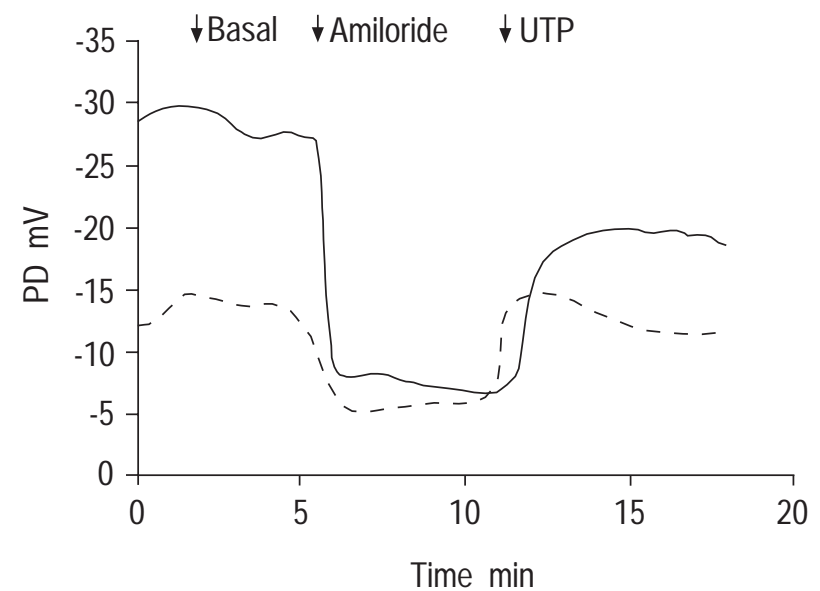

Fig. 1. - Example of nasal potential difference (PD) changes in a cftr ${ }^{\text {tmiHGU }}$ cystic fibrosis (CF) mouse ( - ) and a matched control $(---)$ with the amiloride uridine triphosphate (UTP) combination. The PD is shown at the resting state, followed by application of amiloride causing a fall in PD which is more marked in the CF mouse. Subsequent application of UTP increases the PD and the CF mouse again shows greater changes.

$\mathrm{mmol} \cdot \mathrm{L}^{-1}$ UTP. The action of UTP was also found to be dose dependent from a range of $0.1-10.0 \mathrm{mmol} \cdot \mathrm{L}^{-1}(\mathrm{n}=3$, fig. 4). Higher concentrations did not produce further increase in $\mathrm{PD}$.

\section{Discussion}

The basal PD measurements in the two groups of $\mathrm{CF}$ mice were significantly greater than the controls suggesting an ion transport abnormality similar to that seen in humans. The $\Delta \mathrm{F} 508$ mice had higher nasal PD at rest compared to insertional $\mathrm{CF}$ mice indicating a more severe phenotype. Previous studies in both humans and mice have demonstrated a fall in nasal epithelial PD after amiloride administration $[10,17]$. The expected fall in PD was observed in all groups after administration of the sodium channel blocking agent amiloride. Similar changes have

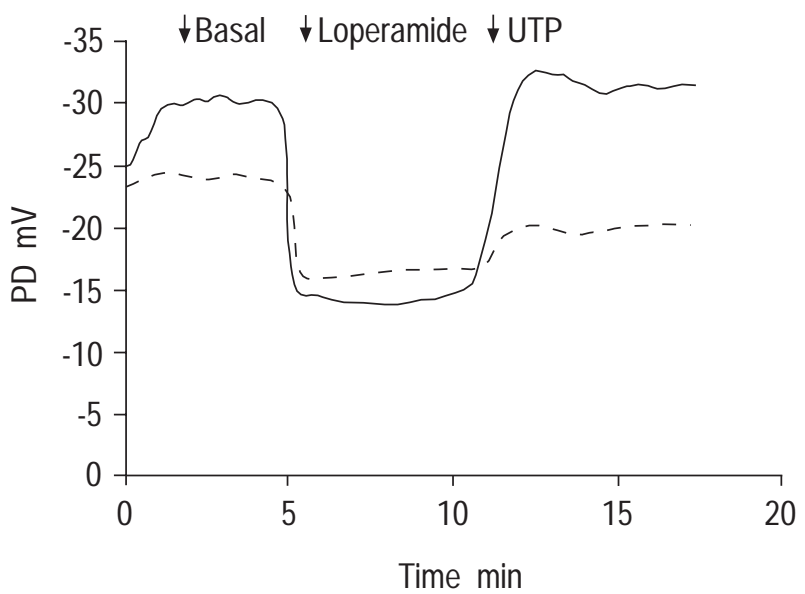

Fig. 2. - Nasal potential difference (PD) changes in a ftrtm $^{1 \mathrm{HGU}}$ cystic fibrosis (CF) mouse (-) and a matched control $\left(--_{-}\right)$with the loperamide uridine triphosphate (UTP) combination. The PD is shown at the resting state, followed by application of loperamide causing a fall in $\mathrm{PD}$ which is more marked in the CF mouse. Subsequent application of UTP increases the PD and the CF mouse again shows greater changes.

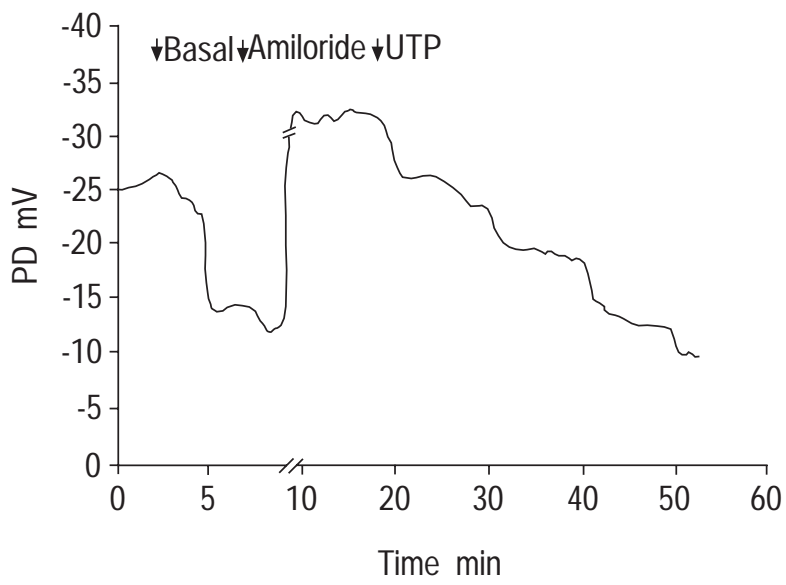

Fig. 3. - Duration of action of a single dose of cystic fibrosis (UTP) 10 $\mathrm{mmol} \cdot \mathrm{L}^{-1}$ in a $\mathrm{cftrtm}^{1 \mathrm{HGU}}$ cystic fibrosis $(\mathrm{CF})$ mouse. The potential difference (PD) is shown at the resting state, followed by application of amiloride causing a fall in PD. Subsequently, the application of UTP increases the PD which declines with time reaching the value of the postamiloride PD after 40-50 min. The action of amiloride remains for up to $4 \mathrm{~h}[14]$ (data not shown).

been shown with loperamide in in vitro studies in the bowel [18]. It has previously been shown that loperamide is effective on the $\mathrm{CF}$ mouse respiratory mucosa as a sodium channel blocker (change in $\triangle \mathrm{PD}-14 \mathrm{mV}$ versus amiloride $-15 \mathrm{mV}$ ) and had a longer duration of action (8 $\mathrm{h}$ versus amiloride $4 \mathrm{~h}$ ) [14]. It has a relatively longer duration of action when administered systemically in humans (time $(t) 0.5$ hours $=11 \mathrm{~h}$ ) when compared to amiloride $(t 0.5=6 \mathrm{~h})$ [19] suggesting that less frequent administration would achieve sufficient sodium channel blockade. A fall in PD was seen with loperamide consistent with $\mathrm{Na}^{+}$blockade. The subsequent addition of UTP $\left(0.1-10 \mathrm{mmol} \cdot \mathrm{L}^{-1}\right)$ dissolved in a chloride-free vehicle increased the PD in all groups suggesting that $\mathrm{Ca}^{2+}$ activated $\mathrm{Cl}^{-}$secretion was occurring.

The resting chloride conductance of the nasal epithelium is reflected by a small increase in negative nasal PD

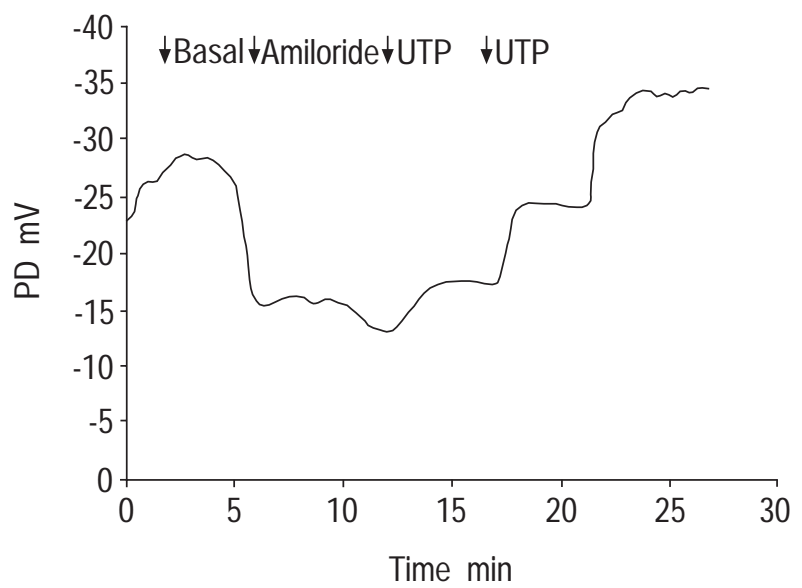

Fig. 4. - The nasal potential difference (PD) changes with logarithmic incremental doses of uridine triphosphate (UTP) from $0.1-10 \mathrm{mmol} \cdot \mathrm{L}^{-1}$ in a ftr $^{\text {tmlHGU }}$ cystic fibrosis (CF) mouse. The PD is shown at the resting state, followed by application of amiloride causing a fall in PD. Increasing doses of UTP $\left(0.1 \mathrm{mmol} \cdot \mathrm{L}^{-1}, 1.0 \mathrm{mmol} \cdot \mathrm{L}^{-1}, 10.0 \mathrm{mmol} \cdot \mathrm{L}^{-1}\right)$ are then applied sequentially from 0.1 to $10 \mathrm{mmol} \cdot \mathrm{L}^{-1}$ with increasing $\mathrm{PD}$ changes as shown. 
following perfusion with a low $\mathrm{Cl}^{-}$solution in the sodium blocked state [20]. This seems to be a necessary step because the PD changes of $\mathrm{Cl}^{-}$secretion are not observed without a low $\mathrm{Cl}^{-}$environment which provides a driving force for apical chloride conductance. However, in the current study, the authors failed to observe any nasal PD change after low $\mathrm{Cl}^{-}$solution was applied to the sodium blocked epithelium by nebulization. It is believed that this is due to differences in the technique of PD measurement: a) the current setup was designed to emulate drug delivery as it would happen in human clinical practice (i.e. by nebulization of droplets containing drug/vehicle which were deposited on the epithelium). Intermittent withdrawal and reinsertion of the nasal recording bridge was necessary to administer the drugs. Other investigators $[10,18,19]$ used a double lumen catheter placed continuously in the nostril throughout the experiment. Various drugs/vehicles were then perfused through one lumen and PD recorded through the other; b) the change in PD following low $\mathrm{Cl}^{-}$solution may be brief. Due to the current technique requiring intermittent withdrawal of the nasal bridge, the authors may be placing the catheter after the PD change has already occurred. This was demonstrated when O. Pirzada and C.J. Taylor (Division of Child Health, University of Sheffield, Sheffield, UK) compared the two methods (personal communication): no change was obtained with nebulization of sodium gluconate after sodium blockade as has been described earlier. However when sodium gluconate was perfused into the nostril preblocked with loperamide, PD changes were observed, which were present as long as the perfusion was continued, but disappeared 1-2 min after the perfusion was stopped; c) difference in depth of catheter placement: Double lumen catheters typically cannot be advanced $>5 \mathrm{~mm}$ into the nostrils [21], but the current nasal catheter usually was sited at a depth of 8-12 mm into the nostril. The authors feel that because of these technical differences they did not observe the changes with low $\mathrm{Cl}^{-}$solution (sodium gluconate) given alone whereas the responses to the drugs were clear and reproducible.

The authors have now demonstrated that the addition of inhaled UTP $\left(0.1-10.0 \mathrm{mmol} \cdot \mathrm{L}^{-1}\right)$ produces a dose dependent change in nasal epithelial PD reflecting $\mathrm{Cl}^{-}$secretion. Higher doses did not produce any further effect. In the presence of amiloride, UTP stimulates $\mathrm{Cl}^{-}$(and water) secretion across normal and $\mathrm{CF}$ airway epithelia via interaction with extracellular 5-nucleotide receptors [22]. The $\mathrm{Cl}^{-}$secretory response is mediated by chloride channels that are activated by $\mathrm{Ca}^{2+}$ mediated pathways. There may be additional therapeutic advantages to the use of UTP. Extracellular nucleotides induce an increase in ciliary beat frequency in human airway epithelia and goblet cell degranulation [23]. UTP alone, or in combination with amiloride, has been shown to increase the rate of whole lung mucociliary clearance three-fold in healthy subjects and the combination of both drugs normalized the low peripheral mucociliary clearance in CF [24].

Purine and pyrimidine nucleotides such as adenosine triphosphate (ATP) and UTP may act on extracellular P2Y receptors linked to G-proteins to produce $\mathrm{Ca}^{2+}$ mobilization and $\mathrm{Cl}^{-}$secretion [25]. The CF mouse nasal tissue was pretreated with nebulized suramin $\left(100 \mu \mathrm{mol} \cdot \mathrm{L}^{-1}\right)$ which is a competitive antagonist of $\mathrm{P} 2$ purinoreceptors $[26$,
27]. Subsequent nebulized application of UTP up to 10 $\mathrm{mmol} \cdot \mathrm{L}^{-1}$ failed to produce any nasal PD change indicating that UTP probably acts on these receptors.

The action of UTP was brief, lasting for 30-40 min after a dose of $10 \mathrm{mmol} \cdot \mathrm{L}^{-1}$. Attempts were made to prolong the action of UTP by the addition of $10 \mathrm{mmol} \cdot \mathrm{L}^{-1}$ alpha beta methylene-adenosine $5^{\prime}$ diphosphate (AMP-CP), a blocker of ectonucleosidases, which regulates the breakdown of monophosphates to purine/pyrimidine + phosphate [28]. However, this was ineffective, suggesting that the breakdown of uridine monophosphate (UMP) to uridine and phosphate is not the rate limiting step in the action of UTP.

Phenotypic and electrophysiological differences exist between CF affected human subjects and mouse models. This partly reflects the proportional species differences between the two main $\mathrm{Cl}^{-}$channels in the airway epithelium, (the CFTR $\mathrm{Cl}^{-}$channels and the $\mathrm{Ca}^{2+}$ activated $\mathrm{Cl}^{-}$ channels) [29], and also the expression of a proportion of wild type CFTR [30] in the mutant mouse lung. The inclusion of functional CFTR, introduced to maintain viability, may explain why the Edinburgh $\mathrm{CF}$ mice in particular have lower than expected nasal epithelial PDs. In the murine bowel however, CFTR mediated $\mathrm{Cl}^{-}$transport plays a major role and alternative $\mathrm{Ca}^{2+}$ mediated $\mathrm{Cl}^{-}$ secretion is absent [27]. Fatal bowel obstruction therefore occurs in a large proportion of knockout CF mice because they have no residual CFTR. However, intestinal obstruction and poor growth was rare in the Edinburgh mice because they express a proportion of wild type CFTR. Thus the proportion of functional CFTR expressed in the Edinburgh mouse may limit the usefulness of this model.

In contrast to the Edinburgh model the $\Delta \mathrm{F} 508$ model of CF mouse has increased basal PD changes and shows a larger response to sodium channel blockers and UTP. Since this model carries the mutation affecting up to $80 \%$ of human $\mathrm{CF}$ patients it may be more relevant model for the study of human disease.

Long acting sodium channel blockers such as loperamide in combination with UTP may have the potential to alleviate CF lung disease by augmenting respiratory mucus hydration, reducing viscosity and increasing mucociliary clearance. However, for practical therapy and convenience, a UTP analogue with similar properties and a longer action is probably required.

In conclusion, the combination of inhaled amiloride loperamide and uridine triphosphate produce nasal potential difference changes suggestive of reduced $\mathrm{Na}^{+}$absorption and increased $\mathrm{Cl}^{-}$secretion in the nasal mucosa of cystic fibrosis mice.

\section{References}

1. Welsh MJ, Fick RB. Cystic fibrosis. J Clin Invest 1987; 80: $1523-1526$

2. Puchelle E, Gaillard D, Ploton D, et al. Differential localization of the cystic fibrosis transmembrane conductance regulator in normal and cystic fibrosis airway epithelium. Am J Respir Cell Mol Biol 1992; 7: 485-491.

3. Rugolo M, Mastrocola T, Whorle C, et al. ATP and A1 adenosine receptor agonists mobilize intracellular calcium and activate $\mathrm{K}^{+}$and $\mathrm{Cl}^{-}$currents in normal and cystic 
fibrosis airway epithelial cells. $J$ Biol Chem 1993; 268: 24779-24784.

4. Kunzelmann K, Kathofer S, Greger R. $\mathrm{Na}^{+}$and $\mathrm{Cl}^{-}$ conductances in airway epithehal cells: increased $\mathrm{Na}^{+}$ conductance in cystic fibrosis. Pflugers Arch 1995; 431: $1-9$.

5. Rayner CF, Rutman A, Dewar A, Cole PJ, Wilson R. Ciliary disorientation in patients with chronic upper respiratory tract inflammation. Am J Respir Crit Care Med 1995; 151: 800-804.

6. Knowles MR, Church NL, Waltner WE, et al. A pilot study of aerosolized amiloride for the treatment of lung disease in cystic fibrosis. N Engl J Med 1990; 322: 11891194.

7. Smith JJ, Travis SM, Greenberg EP, Welsh MJ. Cystic fibrosis airway epithelia fail to kill bacteria because of abnormal airway surface fluid. Cell 1996; 85: 229-236.

8. Knowles MR, Robinson JM, Wood RE, et al. Ion composition of airway surface liquid of patients with cystic fibrosis as compared with normal and diseasecontrol subjects. J Clin Invest 1997; 100: 2588-2595.

9. Mason S, Paradiso AM, Boucher RC. Regulation of transepithehal ion transport and intracellular calcium by extracellular adenosine triphosphate in human normal and cystic fibrosis airway epithelium. Br J Pharmacol 1991; 103: $1649-1656$.

10. Galietta LJ, Zegarra-Moran O, Mastrocola T, Wohrle C, Rugolo M, Romeo G. Activation of $\left.\mathrm{Ca}^{2+}{ }^{2+}\right)$-dependent $\mathrm{K}^{+}$ and $\mathrm{Cl}^{-}$currents by UTP and ATP in CFPAC-1 cells. Pflugers Arch 1994; 426: 534-541.

11. Noone PG, Knowles MR. Trends in therapy of abnormal airway epithelial ion and liquid transport. Monaldi Arch Chest Dis 1993; 48: 140-143.

12. Dorin JR, Dickinson P, Alton EW, et al. Cystic fibrosis in the mouse by targeted insertional mutagenesis. Nature 1992; 359: 211-215.

13. Colledge WH, Abella BS, Southern KW, et al. Generation and characterization of a delta F508 cystic fibrosis mouse model. Nature Genetics 1995; 10: 445-452.

14. Snouwaert JN, Brigman KK, Latour AM, et al. An animal model for cystic fibrosis made by gene targeting. Science 1992; 257: 1083-1088.

15. Davidson DJ, Dorin JR, McLachlan G, et al. Lung disease in the cystic fibrosis mouse exposed to bacterial pathogens. Nature Genetics 1995; 9: 351-357.

16. Ghosal S, Taylor CJ, McGaw J. Modification of the nasal membrane potential difference with inhaled amiloride and loperamide in the CF mouse. Thorax 1996; 51: 12291232.

17. Unal-Maelger $\mathrm{OH}$, Urbanek R. Status of determining the transepithehal potential difference (PD) of the respiratory epithelium in the diagnosis of mucoviscidosis. Monatsschrift Kinderheilhmde 1988; 136: 76-80.

18. Hardcastle J, Hardcastle PT, Read NW, Redfern JS. The action of loperamide in inhibiting prostaglandin-induced intestinal secretion in the rat. Br J Pharmacol 1981; 74: 563-569.

19. ABPI compendium of data sheets. London, Datapharm Limited, 1996-97; pp. 452-648.

20. Grubb B, Vick RN, Boucher RC. Hyperabsorption of $\mathrm{Na}^{+}$ and raised $\mathrm{Ca}\left({ }^{2+}\right)$-mediated $\mathrm{Cl}^{-}$secretion in nasal epithelia of CF mice. Am J Physiol 1994; 266: C1478-C1483.

21. Wilschanski MA, Rozmahel $\mathrm{R}$, Beharry $\mathrm{S}$, et al. In vivo measurements of ion transport in long living CF mice. Biochem Biophys Res Comm 1996; 219: 753-759.

22. Knowles MR, Clarke LL, Boucher RC. Activation by extracellular nucleotides of chloride secretion in the airway epithelia of patients with cystic fibrosis. New Engl $J$ Med 1991; 325: 533-538.

23. Davis CW, Dowell ML, Lethem M, Van-Scott M. Goblet cell degranulation in isolated canine tracheal epithehum: response to exogenous ATP, ADP, and adenosine. Am J Physiol 1992; 262: C1313-C1323.

24. Olivier KN, Bennett WD, Hohneker KW, et al. Acute safety and effects on mucociliary clearance of aerosolized uridine 5 'triphosphate $+/$ - amiloride in normal human adults. Am J Respir Crit Care Med 1996; 154: 217-223.

25. Brown HA, Lazarowski ER, Boucher RC, Harden TK. Evidence that UTP and ATP regulate phospholipase C through a common extracellular $5^{\prime}$ nucleotide receptor in human airway epithelial cells. Mol Pharmacol 1991; 40: 648-655.

26. Wilkinson GF, Purkiss JR, Boarder MR. The regulation of aortic endothelial cells by purines and pyrimidines involves co-existing $\mathrm{P} 2 \mathrm{y}$-purinoceptors and nucleotide receptors linked to phosphohpase C. Br J Pharmacol 1993; 108: 689-693.

27. Conigrave $\mathrm{AD}$, Jiang L. Review: $\mathrm{Ca}\left({ }^{2+}\right)$-mobilizing receptors for ATP and UTP. Cell Calcium 1995; 17: 111-119.

28. Richards SM, Dora KA, Rattigan S, Colquhoun EQ, Clark MG. Role of extracellular UTP in the release of uracil from vasoconstricted hindlimb. Am J Physiol 1993; 264: H233-H237.

29. Clarke LL, Grubb BR, Yankaskas JR, Cotton CU, McKenzie A, Boucher RC. Relationship of a non-cystic fibrosis transmembrane conductance regulator mediated chloride conductance to organ-level disease in CFTR(-/-) mice. Proc Nafl Acad Sci USA 1994; 91: 479-483.

30. Dorin JR, Stevenson BJ, Fleming S, Dickinson P, Alton EW, Porteous DJ. Long term survival of the exon 10 insertional cystic fibrosis mutant mouse is a consequence of low level residual wild type CFTR gene expression. Mamm Genome 1994; 5: 465-472. 